\title{
Profile Description of Students' Thinking Skills on The Topic of Divisions of Integer Number Based on SOLO Taxonomy in Class VII-C SMP Negeri 1 Salatiga
}

\author{
$1^{\text {st }}$ Ira Sulistiani Rahayu \\ Mathematics Education Program \\ Faculty of Education and Teacher \\ Training UKSW \\ Salatiga, Indonesia \\ Co-author: \\ 202013603@student.uksw.edu
}

\author{
$2^{\text {nd }}$ Fitri Anna Fauziyyah \\ Mathematics Education Program \\ Faculty of Education and Teacher \\ Training UKSW \\ Salatiga, Indonesia \\ 202013072@student.uksw.edu
}

\author{
$3^{\text {rd }}$ Kriswandani \\ Mathematics Education Program \\ Faculty of Education and Teacher \\ Training UKSW \\ Salatiga, Indonesia \\ kriswandani@staff.uksw.edu
}

\begin{abstract}
This qualitative descriptive research has aim to describe the students' thinking skill profile of class VII-C of SMP Negeri 1 Salatiga on the topic of the division of integers based on SOLO Taxonomy. SOLO Taxonomy groups students' thinking skill levels into five levels, i.e., pre-structural, uni-structural, multi-structural, relational and extended abstract. The subjects of this research were selected using purposive sampling technique which we chose five students of class VII of SMP N 1 Salatiga. The data were collected through in-depth interview, observation, and essay test methods. This analysis data uses the triangulation technique. Based on the analysis, the results of this research are 1) to solve the problem of determining the day on the same date with different year, all subjects used the thinking skills up to the relational level; 2) to solve the problem of determining the number of zeros in the division of the same number, all research subjects used the thinking skills up to the uni-structural level; 3) to solve the problem of determining the number of zeros in the division of recurring numbers, $80 \%$ of the students used the thinking skills up to multi-structural level and $20 \%$ of the students used thinking skills up to the pre-structural level; and 4) to solve the problem of recurring numbers n-times, $20 \%$ of the students used the thinking skills up to pre-structural level, $40 \%$ of them used the thinking skills up to the relational level, and $40 \%$ used the thinking skills up to the multi-structural level.
\end{abstract}

Keyword-Division of integer number, Thinking skills

\section{INTRODUCTION}

Mathematics is a compulsory subject to be studied at the primary education, secondary education, and higher education because mathematics can develop student's thinking ability. Mathematics can develop the ability to think logically, critically, creatively, systematically and to solve problems. Mathematics is a clear and logical means of thinking, the means to solve the problems of everyday life, the means of recognizing relationship patterns and the generalization of experience, the means to develop creativity, the means to increase the awareness of culture development [1]. Therefore, it is essential for students to learn mathematics. It is a field of science which studies the structure, change, and space patterns.

Thinking is a continuous mental process which involves the work of the brain. Thinking is an activity in which the mind is used to make decisions using the information to find meaning, to make judgments, solve problems or make decisions on a problem based on the information and experience existing in everyday life. Thinking is a dynamic process that can be described by the process. Thinking is a process where the new mental representations are formed through information transformation with complex interactions of mental attributes such as judgment, abstraction, logic, imagination and problem-solving. It is essentially a process of thinking where there are three steps, namely the creation of meaning, forming an opinion and conclusion $[2,3]$. Furthermore, the process undergone in thinking is acquiring knowledge and manipulating it by remembering, analyzing, understanding, judging, reasoning, imagining, and speaking activities [4]. Other, thinking includes activity such as planning, decision making, observing facts, guessing, creativity, and other aspects of thinking [5].

The SOLO Taxonomy is an idea of the cognitive complexity structure or student's responsiveness from the existing level. Every cognitive stage, there are the same and increasing responses from the simple to the abstract one. This theory is known as Structure of the Observed Learning Outcome (SOLO). It is a structure of observed learning result. SOLO Taxonomy is also one of the frameworks that can be used as an evaluation tool to identify the students' thinking ability contained in the problems. The thinking skill level according to SOLO Taxonomy consists of 5 levels namely prestructural, uni-structural, multi-structural, relational, and extended abstract. The pre-structural level cannot 
perform the given tasks or tasks with irrelevant data. The characteristics of pre-structural level are refusing to answer, answering the question immediately based on the observation and emotion without logical basis, repeating the question, or student did not solve the problem because they did not understand with given problem. Usually, this level is achieved by students with the average age of 4-6 years. Students at uni-structural level can use a piece of information in responding to a task (forming a single data), so they can solve the problem simplify. The uni-structural level characteristic can be identified as the ability to conclude based on one concrete suitable data. Students achieve this level with the average age of 7-9 years. In the multi-structural level, the students can use some pieces of information together (studying parallel data). The characteristic of the multi-structural level is the ability to conclude based on one or more data or suitable, stand-alone, or separate concept so the student can solve the problem correctly but they cannot connect it. The average students' age to achieve this level is 10-12 years. In the relational level, the students can combine separate pieces of information to produce a completion of a task. The characteristic of the relational level is the ability to think inductively, to draw conclusions based on suitable data or concept and to observe and relate between the data or concept. Students who reach this level are those with an average age of 13-15 years. The last but not the least, in the extended abstract level, the students can find the general principle from integrated data that can be applied to a new situation (high-level concepts learning). The characteristic of this level is the ability to think inductively and deductively, hold or see the relationship, hypothesize, draw conclusions and apply them to other situations. This highest level is achieved by the students whose average age is more than 16 years [5-7]. Solo Taxonomy helps us to know student's problem-solving ability.

Junior high school or SMP (Sekolah Menengah Pertama) students are generally 13 to 15 years old. Based on the explanation above, SMP students use the relational level. However, not all SMP students are at this level. In this research, there will be shown the students' thinking skills in solving the problem of division of integers and problems on division of repetitive numbers. Therefore, this study aims at describing the thinking skill profiles on the matter of integers based on the SOLO Taxonomy for students of grade VII-C, SMP Negeri 1 Salatiga.

\section{METHODS}

This research is qualitative descriptive research. The subject of this research was selected by using purposive sampling technique that was achieved from 5 students of grade VII-C SMP N 1 Salatiga. The data was collected using two methods namely test and in-depth interview method. Data analyses includes four stages such as data collection, data reduction, data display, and conclusion.

\section{RESULT AND DISCUSSION}

\section{Analysis of Problem Number 1}

Problem Number 1 is about the determination of the day on the same date and different year such as the followings.

After one year of marriage, Mrs. Ina gives birth to her firstborn child on Wednesday. Mrs. Ina has promised that she will hold a gratitude ceremony for her firstborn child after 365 days in the future.

a. On what day will Mrs. Ina hold the gratitude ceremony?

b. If the child was born on September 1, 2015, on what day will the child celebrate the one year birthday?

Division can solve the problem above. The subject must know what information can be used to solve the problem. In this case, the information is the number of days in a year (leap year or not), the number of the days in a week and the use of remaining division result to be able to determine the day in the problem. The followings are the answer to each subject in solving the problem of the determination of a particular day.

The subject's answers to problem 1(a) are as follows in Fig. 1;
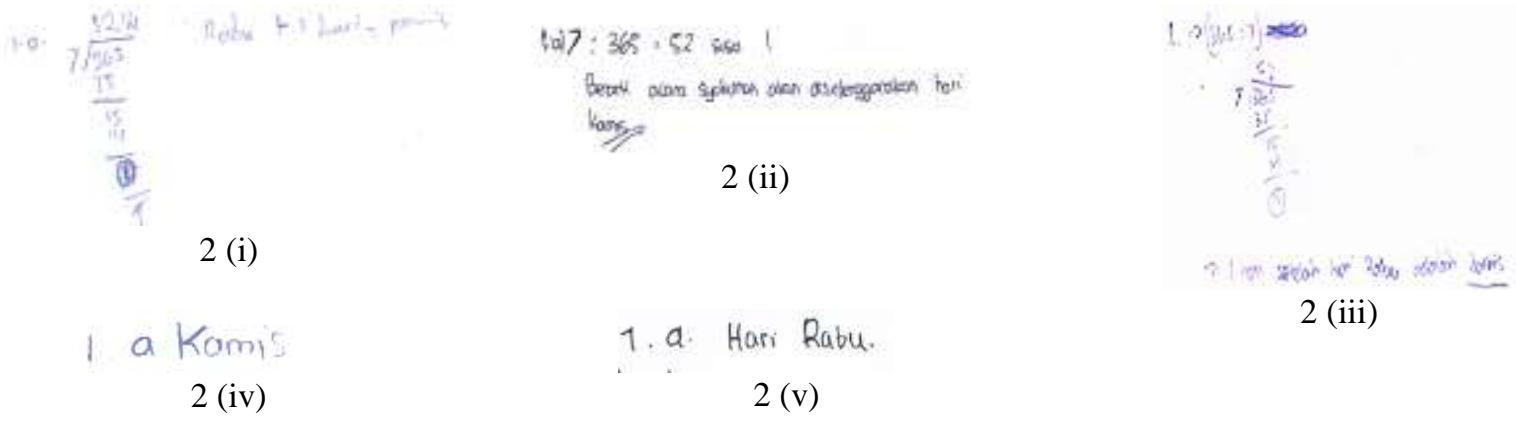

Fig. 1. The answer of each subject about problem 1(a) 
Based on test and interview results in solving problem 1(a), they can finish the problem up to relational level. It can be seen as the subjects are able to combine information obtained from the problem. The information is about the number of days in a year (365 days) and the number of days in a week (7 days). On the other hand, subject four does not include the explanation The Subject's answers to problem 1(b) are as follows.

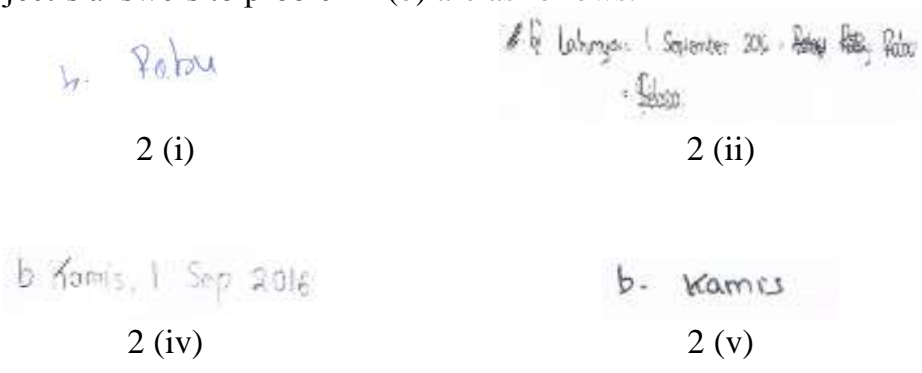

of how to solve the problem, and his answer can be seen in Fig. 1 (iv). The subject then combines both of the information by dividing the number of days in a year by the number of days in a week. After the result of the division is obtained, there is a division result of 1 , and then subject adds one day to the known day in the problem so that the answer to the problem is Thursday.

Fig. 2. The answer of each subject about problem 1(b)

Based on the test and interview results in solving problem 1 (b), the subject has a relational level. In Fig. 2 (i) and (ii), Subject 1 and Subject 2 combine the information obtained from the problem even though the subject once had incorrect information which was the same problem in solving problem 1(a). The subject did not realize that the intended year was a leap year $(366$ days). As a result, the subject assumed that the result of the division of the number of days in a year (365 days) with the number of days in a week ( 7 days) had the remaining number of the day by one that when it was added after Tuesday, the result was Wednesday. During the interview, the subject realized that the intended year was leap year which contains 366 days. The subject discovered a different result that was 2 . Then, the subject added it to the known day so that the answer to the problem was Thursday. In Fig. 2 (iii), Subject 3 combined the information obtained from the problem. The subject once had incorrect information about the number of days in a leap year. The subject did not realize that there were 366 days in a leap year. Therefore, in solving the problem, the subject used the knowledge of a leap year with 369 days then divided it by the number of days in a week ( 7 days) with the result of division 3 so that when it was added to the known day from the problem, the answer was Saturday. The subject recalculated the answer during the interview. After that, the subject realized that a leap year contains 366 days so that the actual result of the division was two. At last, the subject added the number to the known day from the problem to get the correct answer that was Thursday. In Fig. 2 (iv), Subject 4 could solve the problem with no explanation of how to solve it. Based on the knowledge of subject four from the elementary school that generally the days and months going through a year were 365 days then it would be one day late than usual. On the other hand, in a leap year (366 days), the usual day will be late for two days. The subject then added the result to the known day with two so that the answer to the problem was Thursday. Fig. 2 (v) Subject 5 could solve the problem with no explanation of how to solve it. Based on his knowledge, after passing the previous year (365 days), the days would not be different. It happened when the subject was finishing problem 1(b). With this kind of calculation, the answer to the problem was Wednesday, but because the subject was not sure of the result, the subject answered the problem with Thursday without any apparent reason. During the interview, the subject recalculated the answer after getting the information about the days in a leap year and a week. The subject then combined both information by dividing the number of days in a year and a week. The result of the division was 2 . 


\section{Analysis of Problem Number 2}

Problem number 2 is about the determination of the how many zeros are there as the result of the division of a number which consists of a sequence of repeated numbers with the following numbers (not repeated). The examples are as follows:

How many zeros in the result of the following divisions? 2.017: 2.017?

a. 20.172.017: 2.017?

b. $201.720 .172 .017: 2.017$ ?

c. If 30 times of the number 2017 exists, how many zeros are there if it is divided by 2017 ?

d. How many zeros are there from the division of $1234512345 \ldots \ldots .12345: 12345$ ?

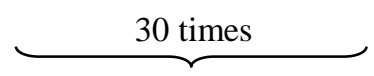

The subject can solve the problem by using the division principle. The followings are the answer to each subject in solving the problem about determining the zeros as the result of the division.

\section{Subject 1}

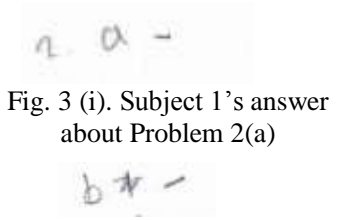

Fig. 3 (ii). Subject 1's answer about Problem 2(b)

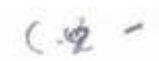

Fig. 3 (iii). Subject 1's answer about Problem 2(c)

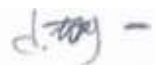

Fig. 3 (iv). Subject 1's answer about Problem 2(d)

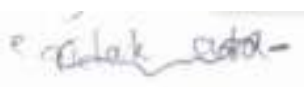

Fig. 3 (v). Subject 1's answer about Problem 2(e)
According to the test and interview results in solving problem 2(a), subject 1 was able to solve the problem up to uni-structural level. It could be seen that during the interview subject recalculated the answer and found that there was no zero (-) in the result of the division.

According to the test and interview results in solving problem 2(b), the subject managed to solve the problem up to multi-structural level. It was because subject 1 could combine the information obtained from the problem. The said information was simple division and the existence of zero from the result of the division even though the subject did not realize it at first. During the interview, the subject recalculated the problem and found out that there were three zeros in the result of the division.

According to the test and interview results in solving the problem 2(c), subject 1 could solve the problem up to multistructural level. It could be seen that the subject could combine the information obtained from the problem. The information was about simple division and the existence of zero as the result of the division. The subject did not realize the existence of the zeros at first until the interview took place.

According to the test and interview results in solving problem 2(d), subject 1 could solve the problem up until relational level. It could be seen that when subject 1 could combine the information obtained from the problem. The information was about simple division, the zeros as the result of the division, and how to solve the problem if the number was repeated 30 times. Even though the subject did not realize the existence of zero in the result of the division and also how to solve the problem, the subject recalculated to solve the problem 2(b) based on the information obtained during the interview. Problem 2(b) had three zeros so that to solve the problem 2(d) the subject reduced the number on the problem (30 times to 2017) with the sum of problem 2(b) (2 times to 2017). As a result of the reduction operation $(30-2)$ the answer was 28 . The result of the zero then multiplied the result of the division in problem 2(b) that was 3 zeros. Thus, the counting operation used was the multiplication of $28 \times 3=84$. The result was still added by 3 so that the number of 2017 was 30 times. Then, the answer to the problem was 87 zeros.

According to test and interview result in solving the problem 2(e), subject 1 could solve the problem up to relational level. It could be seen from the way subject 1 combined the information obtained from the problem. The information was about simple division, zeros from the division result, and also how to solve the problem if the number was repeated 30 times. Even though the subject did not realize how to solve the problem, the subject managed to provide the correct answer during the interview. The subject took two examples of repeated numbers (1234512345) divided by (12345) so that the result was four zeros. As in problem 2(d), then $28 \times 4=112$. The result was still added by 4 so that the number of 12345 was 30 times. Thus, the answer to the problem was 116 zeros. 


\section{Subject 2}

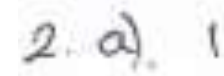

Fig. 4 (i). Subject 2's answer about Problem 2(a)

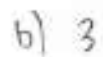

Fig. 4 (ii). Subject 2's answer about Problem 2(b)

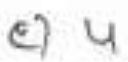

Fig. 4 (iii). Subject 2's answer about Problem 2(c)

\section{0}

Fig. 4 (iv). Subject 2's answer about Problem 2(d)

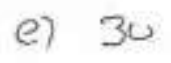

Fig. 4 (v). Subject 2's answer about Problem 2(e)

\section{Subject 3}

Fig. 5 (i). Subject 3's answer about Problem 2(a)

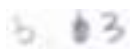

Fig. 5 (ii). Subject 3's answer about Problem 2(b)

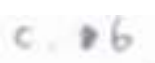

Fig. 5 (iii). Subject 3's answer about Problem 2(c)

Fig. 5 (iv). Subject 3's answer about Problem 2(d)
According to the test and interview results in solving problem 2(a), subject 2 could solve the problem until uni-structural level. It could be seen when the subject was in the interview, the subject recalculated the answer to the problem and got 1 as the answer in which there was no zero in the division result.

According to the test and interview results in solving problem 2(b), subject 2 could solve the problem up until pre-structural level. It can be seen from subject's answer to problem 2(b) that is 3 . The subject got the answer because the subject counted the number of zeros in the problem. During the interview, subject recalculated the answer and found out that the subject could not solve the problem.

According to the test and interview results in solving problem 2(c), subject 2 was considered into pre-structural level when answering the problem. It could be seen from subject's answer to problem 2(c) that is 4 . The subject got the answer because of the number of zeros calculation from the problem. When the subject recalculated the answer to the problem, subject 2 could not solve the problem.

According to the test and interview results in solving problem 2(d), subject 2 managed to solve the problem until pre-structural level. It was because the subject's answer to the problem 2(d) was 30. The answer was obtained by subject 2 because the subject calculated the number of zero in the problem. During the interview, the subject recalculated the problem and admitted that the subject could not solve the problem.

According to the test and interview result in solving problem 2(e), subject 2 could solve the problem up until pre-structural level. It could be seen from the subject's answer to problem 2(e) that is 30 . The subject got the answer from calculating the number of zeros in the problem. During the interview, subject recalculated the problem and admitted that the subject could not solve the problem.

According to the test and interview results in solving problem 2(a), subject 3 was considered into the uni-structural level. It could be seen from the interview result when the subject calculated the answer. There is no zero(-) in the result of the division.

According to the test and interview results in solving problem 2(b), subject 3 could solve the problem up until multistructural level. It was because subject 3 managed to solve the problem by combining the information obtained from the problem. The information was about simple division and the existence of zero from the result of the division. The subject solved the problem by dividing 20172017 by 2017 so that the answer was 3 zeros.

According to the test and interview results in solving problem 2(c), subject 3 could solve the problem up until multistructural level. It was because subject 3 could combine the information obtained from the problem. The information was about simple division and the existence of zero as the result of the division such as in problem 2(b). Subject solved the problem by dividing 201720172017 by 2017 so that the answer to the problem was 6 zeros.

According to the test and interview result in solving problem 2(d), subject 3 could solve the problem until relational level. It could be seen from the way subject 3 combined the information obtained from the problem. The information was about simple division, the numbers of zero as the result of the division and also how to solve the problem if the number was repeated 30 times. The subject managed to solve the problem based on the acquired knowledge from problem 2(b). The problem had 3 zeros so that to solve the problem 2(d), the subject reduced the number in the problem (30 times on 2017) by the sum of problem 2(b) (2 times on 2017). Thus, the answer from reduction operation (30-2) was 28 . The result of zero then multiplied the result in problem 2(b) that was 3 zeros. In conclusion, the calculation operation used was the multiplication of $28 \times 3=84$. The result was still added into 3 so that the number of 2017 was 30 times. The answer to the 


\subsection{0 .916 \\ Fig. 5 (v). Subject 3's answer about Problem 2(e)}

\section{Subject 4}

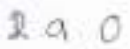

Fig. 6 (i). Subject 4's aAnswer about Problem 2(a)

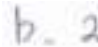

Fig. 6 (ii). Subject 4's answer about Problem 2(b)

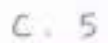

Fig. 6 (iii). Subject 4's answer about Problem 2(c)

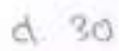

Fig. 6 (iv). Subject 4's answer about Problem 2(d)

Fig. 6 (v). Subject 4's answer about Problem 2(e)

\section{Subject 5}

2. a. Tidak ada (1) problem was 87 zeros.

According to the test and interview results in solving problem 2(e), subject 3 could solve the problem up until relational level. It was because the subject could combine the information obtained from the problem. The information was about simple division, the number of zeros from the division result and how to solve the problem if the number was repeated 30 times. The subject took an example from 2 repeated numbers (1234512345) divided by (12345) so that the result was four zeros as in problem 2 (d) that $28 \times 4=112$. The result was then added by 4 so that the number of 1234530 times then the answer is 116 zeros.

According to the test and interview results in solving problem 2(a), subject 4 managed to solve the problem up until uni-structural level. It was because during the interview, the subject recalculated the answer and there was no zero (0) in the answer.

According to the test and interview results on solving problem 2(b), subject 4 could solve the problem up to multistructural level. It could be seen from the way the subject combined the information obtained from the problem. The information was about simple division and the existence of zero in the division result. Even though the subject only counted the number of zero in the problem so that the result was 2, the subject did not realize the existence of zero in the problem at first. During the interview, the subject recalculated the answer until the subject realized the existence of zero in the result of the problem.

According to the test and interview results in solving problem 2(c), subject 4 managed to solve the problem up until multistructural level. It could be seen when the subject could combine the information obtained from the problem. The information was about simple division and the existence of zero from the result of the division. Even though the subject once only calculated the zeros in the problem so that the answer is 5 , the subject did not realize the existence of the zero in the result of the division. During the interview, the subject recalculated the answer and found out the existence of zero in the result of the division.

According to the test and interview results in solving problem 2(d), subject 4 could solve the problem up until multistructural level. It could be seen from the way subject 4 combined the information obtained from the problem. The information was about simple division and the existence of zero as the result of the division. The subject once only calculated the number of zero in the problem so that there are 30 zeros. Subject 4 did not realize the existence of zero in the result of the division. The subject recalculated the answer during the interview. Later, the subject realized that there was zero in the result of the division. Thus, the way subject 4 solved the problem was based on the knowledge obtained from problem 2(b) that was the existence of three zeros from the result of division 20172017 : 2017 so that the subject multiplied 30 (from the problem) by 3 to get the answer of 90 .

According to the test and interview results in solving problem 2(e), subject 4 could solve the problem until multistructural level. It can be seen from the way subject managed to combine the information obtained from the problem. The information is about simple division and the existence of zero from the result of the division. The subject only calculated the number of zero in the problem to get the answer of zero. It is because there is no zero in the problem. The subject did not realize the existence of zero from the result of the division. During the interview, the subject recalculated the answer. Subject realized that there are zeros in the result of the division so that the way subject 4 solved the problem in the same way with problem 2(d). The subject took two examples of repeated numbers (1234512345) divided by (12345) so that the answer was four zeros. Subject multiplied 30 (from the problem) by 4 that the answer was 120 .

According to the test and interview results in solving problem 2(a), subject 5 could 
Fig. 7 (i). Subject 5 's answer about Problem 2(a)

b. Tidak ado (11)

Fig. 7 (ii). Subject 5's answer about Problem 2(b)

III (Trdak ada nol?

Fig. 7 (iii). Subject 5's answer about Problem 2(c)

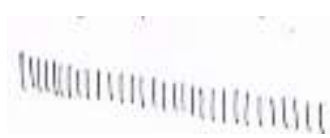

Fig. 7 (iv). Subject 5's answer about Problem 2(d)

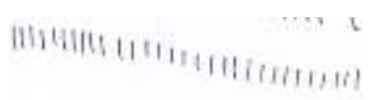

Fig. 7 (v). Subject 5's answer about Problem 2(e) solve the problem until uni-structural level. It could be seen during the interview when the subject recalculated the answer to the problem so that the answer is 1. It was because there was no zero from the result of the division.

According to the test and interview result in solving problem 2(b), subject 5 managed to solve the problem until multistructural level. It could be seen from the way the subject combined the information obtained from the problem. The information was about simple division and the number of zero from the result of the division. The subject was once not realizing the existence of zero from the result of the division so that the subject got 11 as the answer. During the interview, the subject recalculated the division operation in the answer and realized that there are three zeros from the result of the division.

According to the test and interview result in solving problem 2(c), subject 5 could solve the problem until multistructural level. It is because subject 5 could combine the information obtained from the problem. The information was about simple division and the number of zero in the result of the division. At first, the subject did not realize the existence of zero in the result of the division so that the answer was 111 although the subject may not be aware of the zero of the division so that the subject gets answer 111 . During the interview, the subject recalculated the answer to the problem and realized that there are six zeros from the result of the division.

According to the test and interview result in solving problem 2(d), subject 5 could solve the problem until multistructural level. It can be seen from the way subject 5 combined the information obtained from the problem. The information was about simple division and the number of zero in the result of the division and also using the multiplier. The subject once did not realize the existence of zero in the result of the division so that the subject got the answer $11 \ldots 1$. When the interview took place, the subject recalculated the answer with division operation. Later the subject realized that there was zero in the result of the division. Thus, the way subject $\mathrm{HJ}$ solve the problem was based on the things that the subject had known from problem 2 (b). There are three zeros from the result of the division $20172017: 2017$. Therefore, subject calculated the multiples of 3 . It started from 3, 6, 9.... 90 (30 times). The subject did not realize that actually, a multiplier started from 0 instead of 3 because when $2017 \div 2017=1$ is meaning that it did not have zero so that the answer to the problem is 90 zeros.

According to the test and interview results in solving problem 2 (d), subject 5 could solve the problem until multistructural level. It could be seen from the way subject 5 combined the information obtained from the problem. The information is about simple division, the number of zeros in the result of the division and also a multiplier. Even though the subject did not realize that there are zeros in the result of the division so that the subject got $11 \ldots 1$ as the answer, the subject eventually realized that there are zeros in the result of the division during the interview. Thus, the subject solved the problem in the same way of solving problem $2(\mathrm{~d})$. The subject took the example of 2 repeated numbers (1234512345) divided by (12345) so there are four zeros. Therefore, the subject calculated the multiples of 4 . It started at $4,8,12 \ldots 120$ (counted 30 times). The subject did not realize that a multiplier should start from 0 instead of 4 because when $12345 \div 12345=1$ is meaning that it had no zeros so that the answer was 120 zeros.

\section{CONCLUSION}

Based on the written test and interview analysis results from grade VII-C of SMP N 1 students' level of understanding in solving problems of number subject matter, it can be concluded that from the 5th grade VIIC of SMP N 1 student subjects that 1) in order to solve a problem about the same date with different year determination, all the subjects used the thinking skill up to relational level; 2) in order to solve a problem about determination of how many zeros in the result of same number division, all the subjects used the thinking skill up to uni-structural level; 3 ) in order to solve a problem about determination of the number of zeros in repeated number division, $80 \%$ of the students used the thinking skill up to multi-structural level and pre-structural level for the rest of $20 \%$; and 4) in order to solve a problem about n-times repeated number division, $20 \%$ of students used the thinking skill up to pre-structural 
level, $40 \%$ for relational level, and $40 \%$ for multistructural level.

\section{REFERENCES}

[1] Abdurrahman, M., Pendidikan Bagi Anak Berkesulitan Belajar, Jakarta: PT Rineka Cipta, 2009.

[2] Suryabrata, S., Psikologi Pendidikan, Jakarta: PT. Raja Grafindo Persada, 1993

[3] Solso, R.L, Maclin, O.H., Maclin, K., Psikologi Kognitif, Jakarta: Erlangga, 2009.

[4] Pasandaran and Rusli, "Profil Berpikir dalam menyelesaikan masalah aljabar berpandu pada Taksonomi Solo ditinjau dari Tingkat Efikasi Diri pada Siswa SMP Al-Azhar Palu,"
Pedagogy Journal of Mathematic Education, vol. 1(1), 2016

[5] De Bono, Edward, Mengajar Berpikir, Jakarta: Erlangga, 1992.

[6] Hariwijaya, PAUD Melejitkan Potensi Anak dengan Pendidikan Sejak Dini, Yogyakarta: Mahadika Publicity, 2009

[7] Biggs, J.B and Collis, K.F, Evaluating the Quality of Learning the SOLO Taxonomy, New York: Academic Press, 1982, pp. $28-42$.

[8] Sunardi, Hartanto, "Pengembangan Taksonomi 'Solo' Mahasiswa Dalam Aljabar. Seminar Nasional Pendidikan Matematika "Matematika dan Pembelajarannya, Menyongsong Kurikulum 2013"," http://digilib.unipasby.ac.id/files/disk1/12/gdlhub--hartantosu592-1-16.hart-i.pdf, Accessed date June 1st 2013. 